\title{
Trends in pyloric stenosis incidence, Atlanta, 1968 to 1982
}

\author{
EDWARD J LAMMER AND LARRY D EDMONDS
}

From the Birth Defects Branch, Birth Defects and Developmental Disabilities Division, Center for $\vec{\circ}$

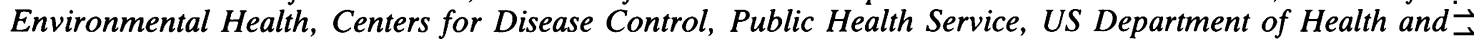
Human Services, Atlanta, Georgia 30333, USA.

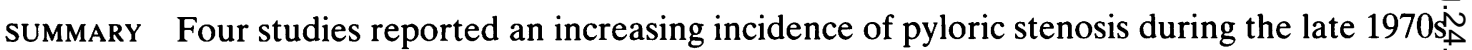
from geographically diverse areas of the United Kingdom. It was suggested that the increasedpo incidence might be related to changes in infant feeding practices. We used data from the Metropolitan Atlanta Congenital Defects Program, a population based birth defects registry, to examine the secular trends and descriptive epidemiology of pyloric stenosis in a North American? city. For the period 1968 to 1982, the incidence of pyloric stenosis was 1.33 per 1000 live births; there was no evidence of an increasing trend for either race or sex specific rates of pyloriøo stenosis. The descriptive epidemiology of the pyloric stenosis cases showed higher rates fore males, whites, and infants of higher birth weight. We found no increasing trend in pyloric stenosis incidence in Atlanta, despite well documented changes in US infant feeding practices (are increased prevalence of breast feeding) during the 1970s.

A marked increase in the incidence of pyloric stenosis was reported in Scotland for 1978 and 1979. ${ }^{1}$ This report was followed by studies that found increases in the incidence of pyloric stenosis in three other areas of the United Kingdom: Greater Manchester, ${ }^{2}$ West Midlands, ${ }^{3}$ and South Glamorgan. ${ }^{4}$ Only the South Glamorgan data, however, showed an increase in pyloric stenosis rates as remarkable as the rise in Scotland. In the other two areas, the increase in incidence was fairly steady between 1974 and 1980, with peaks in 1979. The figure shows a composite of the incidence trends in the four United Kingdom studies. The cause of the increase is undetermined but is unlikely to be due to reporting artefacts. The purpose of our study was to examine the trends of pyloric stenosis incidence in a North American city during the same period in which the incidence rose in several areas of the United Kingdom.

\section{Methods}

Our source of data was the Metropolitan Atlanta Congenital Defects Program (MACDP), a population based birth defects registry that monitors all resident births within the five county Atlanta area.

Received for publication 27 November 1985.

Revised version accepted for publication 5 June 1986.
Infants are registered who have a structural op chromosomal birth defect that is symptomatic orD diagnosed by one year of age. Malformation sur veillance is active and ascertainment of malformed?
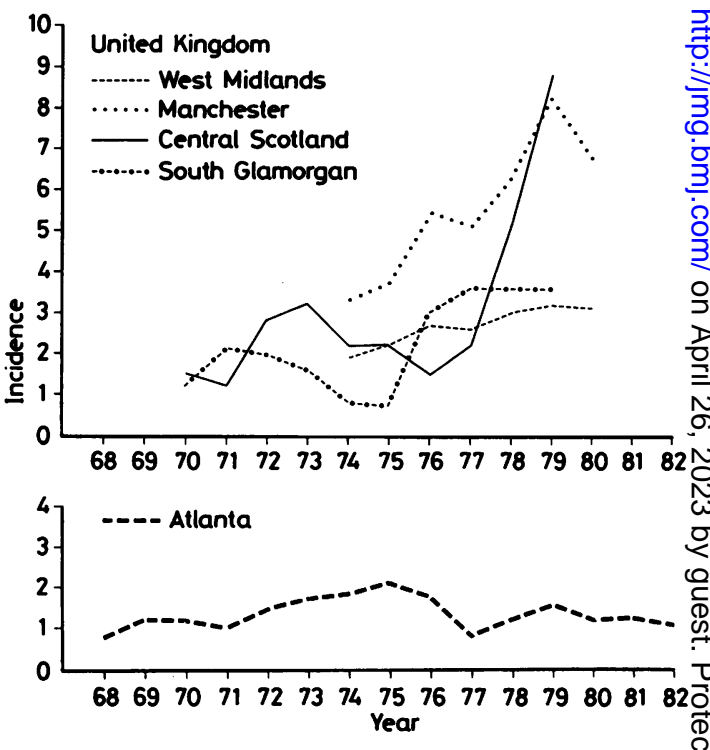

FIGURE Incidence of infantile pyloric stenosis per 1000 live births in five areas, 1968 to 1982. 
infants is hospital based. MACDP personnel review the hospital medical records of infants and their mothers and complete a standard registration form for each malformed infant. The activities and procedures of the MACDP have been described in more detail by Edmonds et al. ${ }^{5}$

Infants were assigned a diagnosis of pyloric stenosis if that diagnosis was listed on the hospital chart or discharge summary. Two methods were used to assess the validity of the diagnoses. First, we analysed the infants' ages at the time their cases were diagnosed. This showed that $9 \%$ of the infants were less than two weeks of age at diagnosis and that $1 \%$ were older than four months. Thus, nearly all of the infants were within the expected age range at diagnosis. Second, from a systematic sample of $20 \%$ of the cases over all years of the study, we determined the percentage of cases in which a pyloromyotomy had been performed. Records showed that in $85(81 \%)$ of the 105 cases sampled, a pyloromyotomy was performed; one infant was diagnosed at necropsy; and in 19 cases the data did not indicate whether surgery was performed. Given that surgical procedures were not systematically recorded on the MACDP records, this survey suggests that a high percentage of the pyloric stenosis cases registered were confirmed surgically.

Denominator data for all live births occurring to residents of the MACDP surveillance area were obtained from vital statistics records of the Maternal and Child Health Division, Georgia Department of Human Resources. Because pyloric stenosis is rarely reported among stillbirths, we restricted the denominator data to live births. The period of study was 1968 to 1982 . During these 15 years, 376524 live births occurred among the residents of the five county Atlanta area. Since $98 \%$ of non-white births in the MACDP area are among black mothers, non-white race will be referred to as black in this study.

Edwards's test for cyclical variation was used to assess seasonal variation. ${ }^{6}$ In this test, the number of cases per month was used as the input variable rather than the rate per month. Because the number of days per month and the number of births per month vary, we adjusted the number of pyloric stenosis cases occurring in each month for both of these factors. The adjusted figures were used in the analysis for seasonal variation.

\section{Results}

INCIDENCE

During the 15 year study period, 518 cases of pyloric stenosis were registered in the MACDP. Table 1 summarises the number of cases and the incidence per 1000 live births for each year, subdivided by sex and race. The incidence of pyloric stenosis in Atlanta changed very little for total cases, males, females, whites, or blacks. There was no evidence of a progressive increase during the second half of the 1970s (figure). Trends were stable for white boys, white girls, black boys, and black girls during 1968 to 1982 . The relative contribution of boys and girls to the total pyloric stenosis rate is apparent in table 1 . The rate for boys is about four times that of girls, independent of race. Table 1 also shows that the rates for white infants are about four times higher than the rates for black infants.

TABLE 1 Incidence* of pyloric stenosis by race and sex, MACDP, 1968 to 1982.

\begin{tabular}{|c|c|c|c|c|c|c|c|c|c|c|}
\hline \multirow{3}{*}{$\begin{array}{l}\text { Year of } \\
\text { birth }\end{array}$} & \multicolumn{4}{|l|}{ Males } & \multicolumn{4}{|c|}{ Females } & \multirow{2}{*}{\multicolumn{2}{|c|}{ Total }} \\
\hline & \multicolumn{2}{|l|}{ White } & \multicolumn{2}{|l|}{ Black } & \multicolumn{2}{|l|}{ White } & \multicolumn{2}{|l|}{ Black } & & \\
\hline & Cases & Rates & Cases & Rates & Cases & Rates & Cases & Rates & Cases & Rates \\
\hline 1968 & 15 & $1 \cdot 52$ & 0 & 0.00 & 5 & 0.52 & () & $0 \cdot(00$ & 20 & 0.76 \\
\hline 1969 & 27 & $2 \cdot 56$ & 0 & $0 \cdot(00$ & 7 & 0.72 & () & 0.00 & 34 & $1 \cdot 24$ \\
\hline 1970 & 30 & 2.69 & 3 & 0.74 & 3 & 0.29 & () & 0.00 & 36 & $1 \cdot 21$ \\
\hline 1971 & 22 & $2 \cdot 27$ & 0 & 0.00 & 5 & 0.52 & 1 & 0.25 & 29 & $1 \cdot(13$ \\
\hline 1972 & 29 & $3 \cdot 23$ & 2 & 0.48 & 6 & 0.71 & () & 0.00 & 37 & 1.45 \\
\hline 1973 & 29 & $3 \cdot 32$ & 3 & 0.72 & 10 & 1.22 & 0 & $0 \cdot(10$ & 42 & 1.67 \\
\hline 1974 & 41 & $4 \cdot 81$ & 0 & 0.00 & 7 & 0.87 & 0 & $0 .(0)$ & 48 & 1.94 \\
\hline 1975 & 37 & $4 \cdot 75$ & 4 & 0.96 & 9 & 1.25 & 1 & 0.26 & 51 & $2 \cdot 21$ \\
\hline 1976 & 30 & 3.99 & 4 & 0.99 & 3 & 0.42 & 2 & $0 \cdot 50$ & 39 & 1.72 \\
\hline 1977 & 15 & 1.94 & 1 & 0.23 & 2 & 0.28 & 1 & 0.23 & 19 & 0.81 \\
\hline 1978 & 20 & $2 \cdot 57$ & 3 & 0.83 & 6 & 0.83 & 0 & $0 \cdot(00$ & 29 & $1 \cdot 19$ \\
\hline 1979 & 21 & $2 \cdot 64$ & 8 & 1.55 & 6 & 0.81 & 3 & $0 \cdot 60$ & 38 & 0.49 \\
\hline 1980 & 21 & $2 \cdot 47$ & 5 & 0.91 & 7 & 0.87 & 1 & 0.19 & 34 & $1 \cdot 24$ \\
\hline 1981 & 25 & $3 \cdot(19$ & 3 & 0.53 & 5 & 0.66 & 0 & 0.00 & 33 & 1.23 \\
\hline 1982 & 19 & $2 \cdot 27$ & 5 & 0.85 & 3 & 0.38 & 2 & 0.35 & 29 & $1 \cdot(x)$ \\
\hline Total & 382 & $2 \cdot 90$ & 41 & 0.61 & 84 & 0.68 & 11 & 0.17 & 518 & 1.33 \\
\hline
\end{tabular}

*Number of cases per $10(\%)$ live births. 
TABLE 2 Distribution* of pyloric stenosis cases by month of birth, MACDP, 1968 to 1982.

\begin{tabular}{llll}
\hline Month & Live births & $\begin{array}{l}\text { Pyloric stenosis } \\
\text { cases (corrected) }{ }^{\dagger}\end{array}$ & Incidence \\
\hline January & 32367 & $47(47 \cdot 0)$ & $1 \cdot 45$ \\
February & 29729 & $40(43 \cdot 8)$ & $1 \cdot 35$ \\
March & 32164 & $32(32 \cdot 1)$ & $0 \cdot 99$ \\
April & 30197 & $34(36 \cdot 7)$ & $1 \cdot 13$ \\
May & 31322 & $38(39 \cdot 3)$ & $1 \cdot 21$ \\
June & 31016 & $45(47 \cdot())$ & $1 \cdot 45$ \\
July & 34194 & $40(38 \cdot 0)$ & $1 \cdot 17$ \\
August & 35035 & $58(53 \cdot 8)$ & $1 \cdot 66$ \\
September & 33901 & $50(47 \cdot 7)$ & $1 \cdot 47$ \\
October & 33370 & $43(41 \cdot 8)$ & $1 \cdot 29$ \\
November & 31917 & $46(46 \cdot 7)$ & 1.44 \\
December & 33061 & $45(44 \cdot 1)$ & $1 \cdot 36$ \\
\hline
\end{tabular}

${ }^{*}$ Edwards's test $\chi^{2}=3 \cdot 44: \mathrm{df}=2 ; 0 \cdot 20>\mathrm{p}>0 \cdot 10$.

tCorrected for variation in number of days per month and number of births per month.

$\ddagger$ Number of cases per 1000 live births

TABLE 3 Distribution of pyloric stenosis cases by birth rank, MACDP, 1968-1982*.

\begin{tabular}{lcc}
\hline Birth rank & Live births $(\%)$ & Pyloric stenosis $(\%)$ \\
\hline 1 & $169593(46 \cdot 8)$ & $211(43 \cdot 9)$ \\
2 & $109545(30 \cdot 2)$ & $157(32 \cdot 6)$ \\
3 & $48726(13 \cdot 4)$ & $55(11 \cdot 4)$ \\
4 & $19(003(5 \cdot 2)$ & $22(4 \cdot 6)$ \\
$5+$ & $15761(4 \cdot 3)$ & $36(7 \cdot 5)$ \\
Missing & 82 & 00 \\
Total & 362710 & 481 \\
\hline
\end{tabular}

*1972 data excluded.

TABLE 4 Distribution of pyloric stenosis cases by birth weight, MACDP, 1968 to 1982*.

\begin{tabular}{lccc}
\hline Birth weight $(g)$ & Live births $(\%)$ & Pyloric stenosis $(\%)$ & Rates $^{\dagger}$ \\
\hline$<2000$ & $11563(3 \cdot 2)$ & $6(1 \cdot 3)$ & $0 \cdot 52$ \\
$200(-2499$ & $19639(5 \cdot 4)$ & $21(4 \cdot 5)$ & $1 \cdot 07$ \\
$25(0)-2999$ & $69280(19 \cdot 1)$ & $74(15 \cdot 8)$ & $1 \cdot 07$ \\
$3(00)-3499$ & $134996(37 \cdot 2)$ & $165(35 \cdot 1)$ & $1 \cdot 22$ \\
$35(0)-3999$ & $92700(25 \cdot 5)$ & $146(31 \cdot 0)$ & $1 \cdot 57$ \\
$4000-4499$ & $24428(6 \cdot 7)$ & $38(8 \cdot 0)$ & $1 \cdot 56$ \\
$\geqslant 4500$ & $589(1 \cdot 6)$ & $20(4 \cdot 3)$ & $3 \cdot 40$ \\
Missing & $4752(1 \cdot 3)$ & $(0)$ & $1 \cdot 31$ \\
Total & 363249 & 470 & \\
\hline
\end{tabular}

*Excludes 1974 data.

+Number of cases per 1000$)$ live births.

\section{SEASONAL VARIATION}

Table 2 shows. pyloric stenosis incidence rates be month of birth. We used Edwards's test ${ }^{6}$ for cyclicad trends to look for evidence of a seasonal variation We did not find a statistically significant single cycle variation $\left(\chi^{2}=3 \cdot 44\right)$.

\section{BIRTH RANK}

Table 3 shows the distribution of 481 pyloric stenosis cases and 362710 live births in Atlanta by birth rank $\overrightarrow{\dot{\vec{H}}}$ Cases and births for 1972 were excluded in this analysis. There was no evidence of higher rates of pyloric stenosis in first born infants $\left(\chi^{2}=1.610\right.$ $\mathrm{p}=0 \cdot 20$ ). The percentage of first born infants with pyloric stenosis was slightly lower than the pero centage of first born live infants in the generado population for white males and females and for black males and females. We did find an excess o pyloric stenosis cases among both white male $\vec{s}$ $\left(\chi^{2}=12 \cdot 4, \quad \mathrm{p}<0 \cdot 001\right)$ and females $\left(\chi^{2}=25 \cdot \frac{\mathrm{C}}{\mathrm{c}}\right.$ $\mathrm{p}<0.001)$ of fifth birth order or higher.

\section{BIRTH WEIGHT}

Table 4 shows the distribution of pyloric stenosis cases and live births by birth weight. Cases and livg births for 1974 were excluded in this analysis Because $\mathrm{Czeizel}^{7}$ had reported an increased rate of pyloric stenosis among infants larger than $3500 \mathrm{~g}$, w\&్ divided the data into groups of less than $3500 \mathrm{~g}$ an equal to or greater than $3500 \mathrm{~g}$ (table 5). A statisti cally significant excess of pyloric stenosis case occurred in the higher weight group $\left(\chi^{2}=17 \cdot 2\right.$ $p<0 \cdot 001)$. When we controlled for the effects of se and race on the incidence of pyloric stenosis. however, the Mantel-Haenszel summary $\chi^{2}$ was nof statistically significant (table 5). Thus, the associab tion of pyloric stenosis and birthweight over $3500 \mathrm{~g}$ was confounded by race and sex. We did find a excess of pyloric stenosis among infants over $4500 \frac{0}{9}$ (crude $\left.\chi^{2}=20 \cdot 1, p<0 \cdot 001\right)$. This association per sisted when the effects of race and sex were controlled (Mantel-Haenszel summary $\chi^{2}=10 \cdot$ $\mathrm{p}=0 \cdot 001)$.

TABLE 5 Distribution* of pyloric stenosis cases by birth weight, sex, and race, MACDP, 1968 to $1982 \%$.

\begin{tabular}{|c|c|c|c|c|}
\hline & \multicolumn{2}{|l|}{$\geqslant 3500 \mathrm{~g}$} & \multicolumn{2}{|l|}{$<3500 \mathrm{~g}$} \\
\hline & Pyloric stenosis & Live births & Pyloric stenosis & Live births \\
\hline White females & 26 & 39621 & 52 & 76763 \\
\hline Black males & 10 & 16816 & 32 & 456.57 \\
\hline Black females & 4 & 11469 & 6 & $60) 748$ \\
\hline Total & 205 & 123085 & 268 & $240) 424$ \\
\hline
\end{tabular}




\section{Discussion}

The crude incidence of pyloric stenosis in Atlanta was stable during 1968 to 1982 . We did not find an increasing incidence during the second half of the 1970s like that reported for four United Kingdom areas. The race and sex specific trends for pyloric stenosis incidence in the MACDP data were also stable. Several other studies of pyloric stenosis trends in geographical areas outside the United Kingdom have failed to show an increasing incidence during the 1970 s. Walpole ${ }^{8}$ studied pyloric stenosis incidence in British Columbia for 1966 to 1977 and found no significant temporal variation in incidence. Rasmussen and Hansen ${ }^{9}$ did not find an increasing incidence in Funen County, Denmark for 1965 to 1983 . The increasing trend in pyloric stenosis rates appears to be unique to the United Kingdom.

In two of the United Kingdom studies, ${ }^{3+}$ the authors suggested that the increased incidence paralleled two major changes in infant feeding practices during the late 1970s: an increasing prevalence of breast feeding and the withdrawal of unmodified cows' milk formula in 1976. Knox et al $^{3}$ referred to a survey in England and Wales in which the percentage of breast fed infants was found to have increased from 51 to $67 \%$ from 1975 to 1980 . For their own study, Knox et $a l^{3}$ did not have information on the type of feeding for the infants; they noted only the ecological parallel of the increasing pyloric stenosis rates and the increasing prevalence of breast feeding. Webb et al, ${ }^{4}$ however, had information for both pyloric stenosis cases and denominator live births regarding the principal type of feeding at one week of age. In that study, the increase in pyloric stenosis incidence began in 1976 to 1977 , and the percentage of mothers breast feeding rose from $33 \%$ during 1974 to 1975 to $45 \%$ during 1976 to 1977 . In the same year (1976) unmodified cows' milk formulae were withdrawn and replaced with formulae designed to approximate more closely to human milk. The data of Webb et $a l^{4}$ showed that the incidence of pyloric stenosis increased in both the breast fed and formula fed infants in the latter half of the 1970s. The relative risk for pyloric stenosis during 1976 to 1979 compared to 1970 to 1975 was 1.9 (95\% confidence interval 0.96 to $3 \cdot 78, p=0 \cdot 07$ ) for breast fed infants and $3.0(95 \%$ confidence interval 1.83 to $5 \cdot(00$, $\mathrm{p}<0.001$ ) for formula fed infants. Although Webb et $a l^{4}$ concluded that there was no appreciable increase in the incidence of pyloric stenosis among the breast fed group, it appears that the incidence increased among both groups. The increased risk was higher for the formula fed infants. This difference could be due to chance or to some interaction between formula feeding and whatever factor was responsible for the increased incidence that occurred in both groups. It is unclear why both formula fed and breast fed infants should have increasing incidences of pyloric stenosis. The association of type of feeding and pyloric stenosis needs further study, since there are few other environmental variables that occur between the time of birth and the onset of pyloric stenosis in the first few months of life.

Infant feeding practices in the United States also underwent remarkable changes during the 1970s. Martinez and Nalezienski ${ }^{10}$ collected information on infant feeding practices at one week of age by mailing a questionnaire to a representative sample of US mothers of infants up to six months of age. They found that the percentage of breast fed infants rose from $25 \%$ in 1970 to nearly $50 \%$ in 1979 . Although we do not have information on trends in infant feeding specific to the Atlanta population, Martinez and Nalezienski ${ }^{10}$ showed that the increasing prevalence of breast feeding occurred in all US geographical regions and among all demographic subgroups for 1978 to 1979 . We have no reason to believe that the trend in breast feeding frequency among Atlanta mothers differed from the national or regional trends. Thus, whereas major increases in the percentage of mothers who breast fed their infants occurred in both Atlanta and the United Kingdom in the 1970s, we did not find a parallel change in the incidence of pyloric stenosis in the United States. Since ecological parallels do not imply causality, the parallel increase in pyloric stenosis in the United Kingdom at a time when breast feeding was increasingly common should be interpreted with great caution.

The aetiology of pyloric stenosis has been reported as multifactorial. Although the genetic contribution has been described by Carter and Evans, the environmental contribution, particularly the contribution most likely to be responsible for marked changes in incidence rates, has not been defined. The environmental factors that have been associated with pyloric stenosis ${ }^{12}$ are unlikely to have changed enough temporally to account for the rise in incidence in the United Kingdom. The maternal use of one environmental factor, Bendectin (Debendox), in the first trimester of pregnancy has been associated with pyloric stenosis in two studies. Eskenazi and Bracken ${ }^{13}$ reported an odds ratio of 4.3 for the association of first trimester Bendectin exposure and pyloric stenosis in a case control study including 35 cases of pyloric stenosis. Using a cohort study design, Aselton et al ${ }^{14}$ supported this finding by reporting a relative risk of 2.5 for pyloric stenosis after Bendectin exposure. Aselton et $a l^{14}$ also found evidence for a dose response effect; 
larger numbers of Bendectin prescriptions were associated with higher relative risks. This association, however, was not confirmed in a much larger case control study of 325 infants with pyloric stenosis. ${ }^{15}$ The latter study had adequate statistical power to detect even a small increase in risk. We agree with Aselton et al ${ }^{14}$ that because of a lack of biological plausibility for a mechanism linking Bendectin exposure and pyloric stenosis, and because of the conflicting results of the epidemiological studies, the association should not be interpreted as causal. For our study, we did not have information on the frequency of Bendectin use among mothers of the infants with pyloric stenosis or of the denominator live born infants.

The descriptive epidemiology of the MACDP pyloric stenosis cases confirmed the associations with some previously reported factors and showed several new findings. An excess of males, with a 4:1 M:F ratio, has been found in nearly every epidemiological study. ${ }^{16}$ We did find a marked racial difference in incidence, with four-fold higher rates in both white males and females compared with blacks. Shim et al ${ }^{12}$ found that the incidence of pyloric stenosis among Oriental and Filipino infants in Hawaii was lower than that among white infants. The US Collaborative Perinatal Study also found racial differences in pyloric stenosis rates. ${ }^{17}$ Participants in that study reported rates of 3.23 per 1000 births for whites $(\mathrm{n}=78)$ and 0.84 per 1000 births for blacks $(n=24)$. This ratio is comparable to that found in our study, although the Collaborative Perinatal Study data did not show a sex difference in rates for blacks.

Several studies have suggested a seasonal incidence for pyloric stenosis, 2161819 but others have not. ${ }^{8} 2021$ We did not find evidence for a seasonal effect. In the studies reporting a seasonal variation, the times of maximum and minimum incidence have not coincided, suggesting that multiple factors may influence the seasonal occurrence and that these may be local. We did not confirm an association between pyloric stenosis and first born birth rank, which had been reported in three previous studies ${ }^{412} 17$ but not in two others. ${ }^{1920} \mathrm{We}$ did find an excess of pyloric stenosis in white infants of high birth order. Interpreting the significance of this association is difficult, since multiparous women probably represent an unusual part of the general population. We did not confirm Czeizel's report of higher rates of pyloric stenosis among males over $3500 \mathrm{~g}^{7}$ In our data, the association of pyloric stenosis and birth weight over $3500 \mathrm{~g}$ was confounded by sex and race. When the effects of these two confounding variables were removed, the association was not statistically significant. We did, however, find an excess of pyloric stenosis amon infants over $4500 \mathrm{~g}$, independent of race and sexp Previous studies found increased rates of pylorie stenosis among higher birth weight infants whem birth weights were stratified, ${ }^{7}{ }^{12}$ but did not finced birth weight differences when mean birth weighs were compared. ${ }^{419}$

In conclusion, we found a stable trend in pyloric stenosis incidence in Atlanta for 1968 to 1982. ThP stable trend occurred during a time of market changes in infant feeding practices, that is, the prevalence of breast feeding was rising, across at demographic subgroups in the United States. TR increase in the prevalence of breast feeding was paralleled in the United Kingdom during the 1970@9 This makes it less likely that the increasing rates $6 \vec{f}$ pyloric stenosis in the United Kingdom might bf attributed to changes in infant feeding practices. The cause of the trend in the United Kingdom is not obvious. It is doubtful that the increasing incidenere in four different geographical areas could be attritbuted to the improved diagnosis or ascertainment of cases. $^{23}$ Pyloric stenosis is aetiologically hetero ogeneous. Because the hypertrophy develops post natally, its occurrence may be sensitive to envirom mental influences, many of which may be local. case control study may be warranted in areas of increasing incidence to assess the role of feeding practices and other factors on the occurrence of pyloric stenosis. The trends in pyloric stenos incidence in the areas of the four United Kingdo studies have not been updated since the results of the studies were originally published, and whethef the incidence will continue to increase remains to be seen.

The authors would like to thank Joyce Smith ang Essie Fuller for their excellent secretarial assistance.

References

1 Kerr AM. Unprecedented rise in incidence of infantile hype trophic pyloric stenosis. $\mathrm{Br}$ Med J 1980;281:714-5.

2 Walsworth-Bell JP. Infantile hypertrophic pyloric stenosis io Greater Manchester. J Epidemiol Commun Health 1983:37:149

3 52 Knox EG, Armstrong E, Haynes R. Changing incidence 尺ิ infantile hypertrophic pyloric stenosis. Arch Dis ChAd 1983;58:582-5.

+ Webb AR, Lari J, Dodge JA. Infantile hypertrophic pyloxic stenosis in South Glamorgan 1970-9: effects of changes im fecding practice. Arch Dis Child 1983;58:586-90.

5 Edmonds LD. Layde PM, James LM, Flynt JW, Erickson Jפ̈, Oakley GP. Congenital malformations surveillance: two Amerp can systems. Int J Epidemiol 1981;10:247-52.

"Edwards JH. The recognition and estimation of cyclic treng Ann Hum Genet 1961;25:83-7.

7 Czeizel A. Birthweight distribution in congenital pyloric ster吕sis. Arch Dis Child 1972;47:978-80. 
× Walpole C. Some epidemiological aspects of pyloric stenosis in British Columbia. Am J Med Genet 1981:10:137-44.

" Rasmussen L, Hansen LP. Incidence of infantile hypertrophic pyloric stenosis in Funen County. Denmark. Lancet 1984:ii:86970

11" Martinez GA. Nalezienski JP. 1980 update: the recent trend in breast-feeding. Pediatrics 1981:67:260-3.

"Carter CO. Evans KA. Inheritance of congenital pyloric stenosis. J Med Genet 1969:6:233-9.

12 Shim WKT. Camphell A. Wright SE. Pyloric stenosis in the racial groups of Hawaii. J Pediatr 1970:76:89-93.

1.5 Eskenazi B. Bracken MB. Bendectin (Debendox) as a risk factor for pyloric stenosis. Am J Obstet Gynecol 1982:144:91924.

${ }^{14}$ Aselton P. Jick H. Chentow SJ, Perera DR, Hunter JR. Rothman KJ. Pyloric stenosis and maternal Bendectin exposure. Am J Epidemiol 1984:120:251-6.

15 Mitchell AA. Schwingel MA. Rosenberg L. Louik C. Shapiro S. Birth defects in relation to Bendectin use in pregnancy. II Pyloric stenosis. Am J Obstet Gynecol 1983:147:737-42.
${ }^{16}$ Dodge JA. Infantilc hypertrophic pyloric stenosis in Belfast. 1957-1969. Arch Dis Child 1975:50:171-8.

17 Myrianthopoulos NC. Chung CS. Congenital malformations in singletons: epidemiologic survey. Birth Defects 1974;X(11):158 .

${ }^{18}$ Kwok RHM, Avery G. Seasonal variation of congenital hypertrophic pyloric stenosis. J Pediatr 1967:70:963-5.

${ }^{19}$ Adelstein P. Fedrick J. Pyloric stenosis in the Oxford Record Linkage Area. J Med Genet 1976;13:439-48.

20) Huguenard JR, Sharples GE. Incidence of congenital pyloric stenosis in birth series. J Chron Dis 1972;25:727-33.

21 Campbell MA. The question of seasonal variation of pyloric stenosis. J Pediatr 1969;74:1006-7.

Correspondence and requests for reprints to Larry Edmonds, Birth Defects Branch, CEH/ Chamblee Building 5, Centers for Disease Control, Atlanta, Georgia 30333, USA. 